Check for updates

Cite this: RSC Adv., 2017, 7, 21205

\title{
Magnetic metal-organic frameworks as scaffolds for spatial co-location and positional assembly of multi-enzyme systems enabling enhanced cascade biocatalysis
}

\begin{abstract}
Sijia Chen, ${ }^{a}$ Liyin Wen, ${ }^{a}$ Frantisek Svec, ${ }^{b}$ Tianwei Tan ${ }^{a}$ and Yongqin Lv (DD *a
Magnetic multi-enzyme nanosystems have been prepared via co-precipitation of enzymes and metalorganic framework HKUST-1 precursors in the presence of magnetic $\mathrm{Fe}_{3} \mathrm{O}_{4}$ nanoparticles. The spatial co-localization of two enzymes was achieved using a layer-by-layer positional assembly strategy. Glucose oxidase (GOx) and horseradish peroxidase (HRP) were used as the model enzymes for cascade biocatalysis. By controlling the spatial positions of enzymes, three bienzyme nanosystems GOx@HRP@HKUST-1@ $\mathrm{Fe}_{3} \mathrm{O}_{4}, \mathrm{GOx}-\mathrm{HRP}$ aHKUST-1@ $\mathrm{Fe}_{3} \mathrm{O}_{4}$ and HRPaGOx@HKUST-1@ $\mathrm{Fe}_{3} \mathrm{O}_{4}$ were prepared in which GOx and HRP containing layers were in close proximity, either encapsulated in the HKUST-1 inner layer, or immobilized on the HKUST-1 outer shell, or randomly distributed in the two MOF layers. Their properties were characterized by transmission electron microscopy, energydispersive X-ray spectroscopy, Fourier transform infrared spectroscopy, X-ray diffraction, thermal gravimetric analysis, and zeta potential measurements. The highest activity was observed at $\mathrm{pH}=6$ and a temperature of $20{ }^{\circ} \mathrm{C}$. Thanks to the favorable positioning of enzymes, the GOx@HRP@HKUST$1 \mathrm{aFe}_{3} \mathrm{O}_{4}$ nanosystem revealed superior kinetics with a Michaelis constant $K_{\mathrm{m}}=0.8 \mathrm{mmol} \mathrm{L}^{-1}$ and the maximum reaction rate $V_{\max }=11.3 \mu \mathrm{mol} \mathrm{L} \mathrm{L}^{-1} \mathrm{~min}^{-1}$. The enzyme-HKUST-1 conjugates exhibited remarkably high operational stability compared to the free enzymes. This work provides a facile and versatile approach to spatially organized multienzyme systems with well-defined nanostructures and greatly enhanced the overall biocatalytic efficiency.
\end{abstract}

Received 24th February 2017

Accepted 7th April 2017

DOI: 10.1039/c7ra02291c

rsc.li/rsc-advances alternative to the complex in vivo architecture is to biomimetically construct an immobilized multienzyme system that would enable efficient cascade biotransformations "in vitro". Several attractive materials and successful strategies have been proposed leading to the design of an arsenal of multienzyme systems for mimicking the natural metabolic pathways in vitro. Examples are the preparations of hydrogels, ${ }^{15,22}$ hourglass shaped nanochannel reactor, ${ }^{23}$ mesoporous silica nanoparticles, ${ }^{\mathbf{1 8 , 2 4}}$ formation of inorganic nanocrystal-protein complexes ${ }^{25}$ and self-assembled crystals, ${ }^{26}$ microbeads, ${ }^{27,28}$ DNA nanostructures, ${ }^{4,5,11,29-31}$ polymersomes, ${ }^{14,32}$ nanoparticles, ${ }^{33}$ nanofibers, ${ }^{13,16,34}$ graphene,, 35 and metal-organic frameworks (MOFs). ${ }^{17,36,37}$

In contrast to other scaffolds, MOFs, which are formed by the self-assembly of metal ions and organic linkers, feature ultrahigh surface area and porosity, uniform pores with tunable sizes, surfaces with variable chemistries, and structural diversity. ${ }^{38}$ The large surface area and uniform pore sizes of MOFs enhance capacity for enzyme immobilization and facilitate mass transport. Furthermore, MOFs can exhibit strong hydrophobic interactions with immobilized enzymes that avert their leakage during operation. ${ }^{39}$ Most importantly, MOFs enable the retention of enzyme activity upon
${ }^{a}$ Beijing Key Laboratory of Bioprocess, College of Life Science and Technology, Beijing University of Chemical Technology, Beijing 100029, China. E-mail: lvyq@mail.buct. edu.cn

${ }^{b}$ Beijing Advanced Innovation Center for Soft Matter Science and Engineering, Beijing University of Chemical Technology, Beijing 100029, China 
harsh conditions that normally cause loss of the catalytic activity. ${ }^{40}$

Our previous study focused on protein encapsulation mechanism in MOFs using molecular dynamic simulations also revealed that MOFs can function as a new category of host materials and molecular chaperones that support the protein folding and prevent their deactivations. ${ }^{41}$ However, restricted by the microporous regime $(<2 \mathrm{~nm})$ of most reported MOFs, the direct encapsulation of enzymes in MOFs remains a significant challenge since enzymes have typically at least one dimension in a range of 3-5 $\mathrm{nm}$. This drawback can be circumvented using a "one-pot" co-precipitation approach in which enzymes are mixed with MOF precursors. The MOF scaffold is then formed in an aqueous buffer at room temperature. ${ }^{17,36,42-44}$ Particularly, Wu $e t$ al. used successfully this strategy to the preparation of a bienzyme nanosystem containing glucose oxidase (GOx) and horseradish peroxidase (HRP) encapsulated in zeolitic imidazolate framework ZIF-8. ${ }^{17}$ At the same time, Hou et al. reported a mimic GOx@mZIF-8 multienzyme system in which magnetic MOF acted as a mimetic peroxidase. ${ }^{36}$

Although the use of multienzyme conjugates is well demonstrated, many challenges remain in the development of new general approaches enabling the accurate control of positioning and orientation of enzymes, creation of spatially organized multienzyme systems with well-defined nanostructures, as well as in the investigation of the comprehensive kinetics., ${ }^{3,29,45}$ Several successful attempts have been proposed to attain these goals. For example, Vriezema et al. designed polymersome nanoreactors to selectively encapsulate three enzymes, Candida antarctica lipase B (CALB), GOx, and HRP. ${ }^{32}$ Garcia adopted a layer-by-layer assembly strategy using biotin-avidin interactions to achieve the desired spatial co-localization of GOx and HRP on magnetic $\mathrm{Fe}_{3} \mathrm{O}_{4}$ nanoparticles. ${ }^{33}$ Liu's group constructed the same bienzyme system based on the formation of the $\mathrm{Cu}^{2+}$-protein nanocrystal complexes. ${ }^{25}$ Polyelectrolyte doped hollow fibers were prepared by Zhang's group to accomplish the accurate control of enzyme positions in two multienzyme systems..$^{13,34}$

Here we report the construction of magnetic metal-organic framework HKUST-1 as scaffold for spatial co-localization and positional assembly of two model enzymes, GOx and HRP. As opposed to previously reported work ${ }^{17}$ in which the multienzymes were randomly distributed in ZIF-8, in our work, GOx and HRP were spatially co-localized in the HKUST-1 MOF structure via a layer-by-layer positional assembly strategy, with GOx on the outer shell and HRP within the pores of the MOF crystal and vice versa. The use of magnetic nanoparticles enables easy separation of biocatalyst from products using a magnet thus facilitating reusability of the catalyst. We systematically investigated the effects of MOF design, optimized the reaction conditions for each bienzyme nanosystem, and studied effects of spatial co-localization of enzymes.

\section{Experimental}

\section{Materials and reagents}

Ferric chloride hexahydrate, 1,3,5-benzenetricarboxylic acid $\left(\mathrm{H}_{3} \mathrm{BTC}\right)$, potassium sodium tartrate tetrahydrate, 3,5- dinitrosalicylic acid, phenol, $o$-phenylenediamine (OPD), 2,3diaminophenazine (DAP), and $\mathrm{D}-(+)$-glucose were all purchased from J\&K Scientific Ltd. (Beijing, China). Sodium citrate, ethylene glycol, sodium acetate anhydrous, and sodium hydroxide were obtained from Sinopharm Chemical Reagent Co., Ltd (Beijing, China). Horseradish peroxidase (lyophilized, activity $\sim 179.2 \mathrm{U} \mathrm{mg}^{-1}$ ) and glucose oxidase (Aspergillus niger, activity $\sim 174.9 \mathrm{U} \mathrm{mg}^{-1}$ ) were purchased from Sigma-Aldrich (St. Louis, MO, USA).

\section{Instrumentation}

The transmission electron microscopy (TEM) images of magnetic nanoparticles were obtained using a HITACHIH800 transmission electron microscope (Hitachi, Ltd., Japan) with an electron acceleration energy of $200 \mathrm{kV}$. Scanning electron microscopy (SEM) images of magnetic nanoparticles were examined using a JEOL JSM-6700F field emission scanning electron microscope (SEM) (Hitachi HighTechnologies, Tokyo, Japan) operated at $5 \mathrm{kV}$. X-ray powder diffraction (XRD) measurements were performed on a $\mathrm{D} / \mathrm{max}-$ UltimaIII (Rigaku Corporation, Japan). Fourier transform infrared spectroscopy (FTIR) was carried out using a Nicolet 6700 (Thermo Fisher Scientific, USA). The zeta potentials were determined using a Zetaplus instrument (BI-90Plus Brookhaven Instruments Corp). The thermal gravimetric analysis was carried out using a Thermogravimetric Analyzer (TGA) (Perkin Elmer, Pyris Diamond S(II), USA) at a heating rate of $10{ }^{\circ} \mathrm{C} \mathrm{min}{ }^{-1}$ in temperatures range $25-800{ }^{\circ} \mathrm{C}$ under

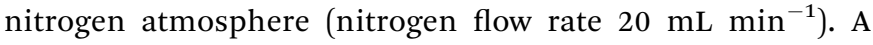
ThermoFisher Ultimate 3000 LC system was used for the reversed-phase chromatographic determination of protein concentrations using a $\mathrm{C}_{18}$ stainless steel column $(25 \mathrm{~cm} \times$ $4.6 \mathrm{~mm}$ i.d.), and the eluted compounds were detected at $280 \mathrm{~nm}$

\section{Preparation of HKUST-1@ $\mathrm{Fe}_{3} \mathrm{O}_{4}$ nanoparticles}

The preparation of citric acid-coated $\mathrm{Fe}_{3} \mathrm{O}_{4}$ nanoparticles was carried out according to previous work. ${ }^{46,47}$ To obtain HKUST1@ $\mathrm{Fe}_{3} \mathrm{O}_{4}$ nanoparticles, $50 \mathrm{mg}$ citric acid-coated $\mathrm{Fe}_{3} \mathrm{O}_{4}$ nanoparticles were well dispersed in $1 \mathrm{~mL}$ deionized water followed by the addition of $1 \mathrm{~mL} 10 \mathrm{mmol} \mathrm{L}^{-1}$ copper(II) acetate. After mechanical stirring at $1200 \mathrm{rpm}$ and $25{ }^{\circ} \mathrm{C}$ for $1 \mathrm{~h}$, the $\mathrm{Cu}^{2+} @ \mathrm{Fe}_{3} \mathrm{O}_{4}$ product was thoroughly washed with water and separated using a magnet. The $\mathrm{Cu}^{2+} @ \mathrm{Fe}_{3} \mathrm{O}_{4}$ nanoparticles were then re-dispersed in $1 \mathrm{~mL}$ water followed by the addition of 1 $\mathrm{mL} 10 \mathrm{mmol} \mathrm{L}^{-1}$ 1,3,5-benzenetricarboxylic acid $\left(\mathrm{H}_{3} \mathrm{BTC}\right)$. The mixture was mechanically stirred at $1200 \mathrm{rpm}$ and $25^{\circ} \mathrm{C}$ for $1 \mathrm{~h}$ to obtain the $\mathrm{H}_{3} \mathrm{BTC} @ \mathrm{Cu}^{2+} @ \mathrm{Fe}_{3} \mathrm{O}_{4}$ nanoparticles. After washing with methanol and water, the $\mathrm{H}_{3} \mathrm{BTC} @ \mathrm{Cu}^{2+} @ \mathrm{Fe}_{3} \mathrm{O}_{4}$ nanoparticles were re-dispersed in $1 \mathrm{~mL}$ water and mixed with

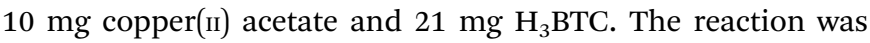
carried out at $25^{\circ} \mathrm{C}$ for $8 \mathrm{~h}$ by mechanical stirring at $1200 \mathrm{rpm}$ to generate the first HKUST-1 layer. The second layer of HKUST-1 was formed using the same synthetic approach. The final product was washed thoroughly with water and separated using a magnet. 


\section{Design of GOx/HRP bienzyme nanosystems}

For the preparation of GOx@HRP@HKUST-1@ $\mathrm{Fe}_{3} \mathrm{O}_{4}$ nanosystem in which GOx was immobilized on the outer HKUST-1 shell and HRP was encapsulated in the inner HKUST-1 layer, the $\mathrm{H}_{3} \mathrm{BTC} @ \mathrm{Cu}^{2+} @ \mathrm{Fe}_{3} \mathrm{O}_{4}$ nanoparticles were first mixed with 1 $\mathrm{mL}$ aqueous solution containing $10 \mathrm{mg}$ copper(II) acetate, $21 \mathrm{mg}$ $\mathrm{H}_{3} \mathrm{BTC}$, and $3 \mathrm{mg} \mathrm{HRP}$, and then reacted under mechanical stirring at $1200 \mathrm{rpm}$ and $25^{\circ} \mathrm{C}$ for $8 \mathrm{~h}$ to produce the first HRP inner layer. After flushing with water, the nanoparticles were mixed with $1 \mathrm{~mL}$ aqueous solution consisting of $10 \mathrm{mg}$ copper(II) acetate, $21 \mathrm{mg} \mathrm{H}_{3}$ BTC, and a specific amount of GOx, and reacted for another $8 \mathrm{~h}$ to form the GOx outer layer. The final product was washed thoroughly with water and separated using a magnet.

For HRP@GOx@HKUST-1@ $\mathrm{Fe}_{3} \mathrm{O}_{4}$ nanosystem in which HRP was immobilized at the outer HKUST-1 shell and GOx encapsulated in the inner HKUST-1 layer, the $\mathrm{H}_{3}$ BTC@ $\mathrm{Cu}^{2+} @ \mathrm{Fe}_{3} \mathrm{O}_{4}$ nanoparticles were first mixed with $1 \mathrm{~mL}$ aqueous solution containing $10 \mathrm{mg}$ copper(II) acetate, $21 \mathrm{mg}$ $\mathrm{H}_{3}$ BTC, a specific amount of GOx, and then reacted under mechanical stirring at $1200 \mathrm{rpm}$ and $25{ }^{\circ} \mathrm{C}$ for $8 \mathrm{~h}$ to produce the first GOx inner layer. After flushing with water, the nanoparticles were mixed with an aqueous solution comprising $10 \mathrm{mg}$ copper(II) acetate, $21 \mathrm{mg} \mathrm{H}_{3} \mathrm{BTC}$, and $3 \mathrm{mg} \mathrm{HRP}$, and reacted for $8 \mathrm{~h}$ to generate the HRP outer layer. The final product was washed thoroughly with water and separated using a magnet.

With GOx-HRP@HKUST-1@Fe $\mathrm{O}_{4}$ nanosystem in which the two enzymes were randomly distributed within the two HKUST1 layers, the $\mathrm{H}_{3} \mathrm{BTC} @ \mathrm{Cu}^{2+} @ \mathrm{Fe}_{3} \mathrm{O}_{4}$ nanoparticles were first mixed with an aqueous solution containing $10 \mathrm{mg}$ copper(II) acetate, $21 \mathrm{mg} \mathrm{H}_{3}$ BTC, $1.5 \mathrm{mg} \mathrm{HRP}$, and a certain amount of GOx, and then reacted under mechanical stirring at $1200 \mathrm{rpm}$ and $25{ }^{\circ} \mathrm{C}$ for $8 \mathrm{~h}$ to produce the first GOx-HRP layer. The second GOx-HRP layer was prepared using the same synthetic approach. The final product was washed thoroughly with water and separated using a magnet.

The GOx@HKUST-1@ $\mathrm{Fe}_{3} \mathrm{O}_{4}$ nanosystem was prepared by

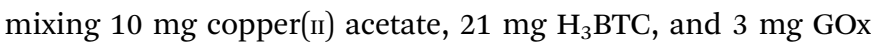
with $\mathrm{H}_{3} \mathrm{BTC} @ \mathrm{Cu}^{2+} @ \mathrm{Fe}_{3} \mathrm{O}_{4}$ nanoparticles, and then reacting under mechanical stirring at $1200 \mathrm{rpm}$ and $25{ }^{\circ} \mathrm{C}$ for $8 \mathrm{~h}$. The final product was washed thoroughly with water and separated using a magnet.

The HRP@HKUST-1@ $\mathrm{Fe}_{3} \mathrm{O}_{4}$ nanosystem was prepared by mixing $10 \mathrm{mg}$ copper(II) acetate, $21 \mathrm{mg} \mathrm{H}_{3} \mathrm{BTC}$, and $3 \mathrm{mg}$ HRP with $\mathrm{H}_{3} \mathrm{BTC} @ \mathrm{Cu}^{2+} @ \mathrm{Fe}_{3} \mathrm{O}_{4}$ nanoparticles, and then reacting under mechanical stirring at $1200 \mathrm{rpm}$ and $25{ }^{\circ} \mathrm{C}$ for $8 \mathrm{~h}$. The final product was washed thoroughly with water and separated using a magnet.

All the experiments were performed in triplicates.

\section{Calculation of enzyme loading}

The enzyme loading $(Q)$ of different bienzyme nanosystems was calculated according to eqn (1):

$$
Q=\frac{\left(C_{0}-C\right) V}{m}
$$

where $C_{0}$ is the initial enzyme concentration before immobilization $\left(\mathrm{mg} \mathrm{mL}^{-1}\right), C$ is the final enzyme concentration in the supernatant after immobilization $\left(\mathrm{mg} \mathrm{mL}^{-1}\right), V$ is the volume of enzyme solution (mL), and $m(\mathrm{mg})$ is the dry weight of HKUST1@ $\mathrm{Fe}_{3} \mathrm{O}_{4}$ nanocomposite used for enzyme immobilization.

\section{Determination of residual glucose concentrations using DNS reagent}

The DNS reagent was first prepared by mixing $0.65 \mathrm{~g} \mathrm{3,5-dini-}$ trosalicylic acid, $2.1 \mathrm{~g}$ sodium hydroxide, and $0.5 \mathrm{~g}$ phenol in $100 \mathrm{~mL}$ hot aqueous solution containing $1.29 \mathrm{~mol} \mathrm{~L}^{-1}$ potassium sodium tartrate. The mixture was then allowed to cool in an ice bath. For the determination of residual glucose concentrations, $1 \mathrm{~mL}$ reaction solution was mixed with $1 \mathrm{~mL}$ DNS reagent, and kept in a boiling water bath for $15 \mathrm{~min}$. The glucose derivative was determined using Thermo Scientific Microplate Reader (Thermo Labsystems Multiskan Spectrum) with detection at $540 \mathrm{~nm}$.

\section{Cascade kinetics study}

The cascade kinetics studies for the bienzyme nanosystems were performed using glucose and $o$-phenylenediamine (OPD) as substrates. The oxidation of glucose by $\mathrm{GOx} / \mathrm{O}_{2}$ produces gluconic acid and $\mathrm{H}_{2} \mathrm{O}_{2}$ intermediate. The HRP then catalyzes the oxidation reaction of OPD with $\mathrm{H}_{2} \mathrm{O}_{2}$ to 2,3diaminophenazine (DAP), which can be recorded by spectrophotometer at $418 \mathrm{~nm}$. The $1 \mathrm{~mL}$ glucose solution with concentrations ranging from $0.56 \mathrm{mM}$ to $111.1 \mathrm{mM}$ was added to the bienzyme systems containing $101 \mathrm{mM}$ OPD in phosphate buffer $(\mathrm{pH}=7)$. The reaction mixture was then incubated at $25{ }^{\circ} \mathrm{C}$ while protecting from light for a defined reaction time. The assay solution was then analyzed immediately by UV/Vis spectrophotometry at $418 \mathrm{~nm}$ to determine the concentration of produced DAP.

\section{Enzyme activity}

Enzyme activity studies were carried out following Zore et al. work. ${ }^{9}$ The activity unit was defined as the amount of enzymes required to convert $1 \mu \mathrm{mol}$ glucose to gluconic acid in $1 \mathrm{~min}$ at pH 6 and $20{ }^{\circ} \mathrm{C}^{\mathbf{1 3}}$ All experiments were performed in triplicates.

\section{Results and discussion}

Preparation and characterization of magnetic metal-organic framework

We first prepared magnetic metal-organic framework HKUST-1. This MOF was selected since it features good solvent resistance and stability. ${ }^{46,47}$ HKUST-1 is prepared under mild conditions that are well suited for encapsulation of enzymes. The citric acid-coated magnetic $\mathrm{Fe}_{3} \mathrm{O}_{4}$ nanoparticles were prepared using a modified solvothermal reaction including reduction of $\mathrm{Fe}(\mathrm{III})$ ions with trisodium citrate in the presence of ethylene glycol. The magnetic HKUST-1 was then prepared using the "one-pot" co-precipitation approach in which $\mathrm{Cu}(\mathrm{II})$ ions coordinated with 1,3,5-benzenetricarboxylic acid in the presence of the magnetic $\mathrm{Fe}_{3} \mathrm{O}_{4}$ nanoparticles. 
The $\mathrm{Fe}_{3} \mathrm{O}_{4}$ and HKUST-1@ $\mathrm{Fe}_{3} \mathrm{O}_{4}$ were imaged in transmission electron microscopy and scanning electron microscopy. Fig. 1a shows the spherical $\mathrm{Fe}_{3} \mathrm{O}_{4}$ magnetic nanoparticles that had an average diameter of $216 \mathrm{~nm}$. The co-precipitation approach successfully generated a HKUST-1 MOF shell with an average thickness of $19 \mathrm{~nm}$ on the surface of $\mathrm{Fe}_{3} \mathrm{O}_{4}$ nanoparticles (Fig. 1b and c). The HKUST-1@Fe $\mathrm{O}_{4}$ nanocomposites were well dispersed. Comparing Fig. $1 \mathrm{~b}$ and $\mathrm{c}$ revealed that repeating the co-precipitation step for another $8 \mathrm{~h}$ led to the formation of a much thicker MOF layer with an average thickness increased to $40 \mathrm{~nm}$. The SEM images in Fig. 2a and b also clearly demonstrate the successful creation of MOF nanocrystal aggregates and significantly increased particle size of the HKUST-1@ $\mathrm{Fe}_{3} \mathrm{O}_{4}$ nanocomposites.

$\mathrm{X}$-ray diffraction (XRD) patterns illustrated in Fig. 3a include all diffraction peaks typical of magnetite (JCPDS card no. 19-0629). After the formation of HKUST-1 layers, new peaks were observed which corresponded to the formation of HKUST-1 crystals. The FTIR spectra of $\mathrm{Fe}_{3} \mathrm{O}_{4}$ nanoparticles and their modified counterparts shown in Fig. 3b exhibit characteristic peak centered at $1630 \mathrm{~cm}^{-1}$ (black line) assigned to the $\mathrm{C}=\mathrm{O}$ stretching vibrations of citric acid groups at $\mathrm{Fe}_{3} \mathrm{O}_{4} \cdot{ }^{47}$ The peak centered at $582 \mathrm{~cm}^{-1}$ corresponds to $\mathrm{Fe}-\mathrm{O}$ stretching. ${ }^{36}$ A large broad band at $3400-3500 \mathrm{~cm}^{-1}$ is attributed to the $\mathrm{O}-\mathrm{H}$ bond stretching. The formation of HKUST-1 layer shifted the peak of $\mathrm{C}=\mathrm{O}$ stretching vibrations to 1710 $\mathrm{cm}^{-1}$. The prominent peaks centered at $1570 \mathrm{~cm}^{-1}$ and 1623 $\mathrm{cm}^{-1}$ are characteristic of the aromatic rings of HKUST-1. The peaks in the range of $1100-1600 \mathrm{~cm}^{-1}$ are ascribed to the vibrational and bending modes of $\mathrm{H}-\mathrm{O}-\mathrm{H}$, the vibrational peaks of $\mathrm{C}-\mathrm{H}$, and stretching vibration peak of $\mathrm{C}-\mathrm{O}$, respectively. ${ }^{\mathbf{4 8 , 4 9}}$ Owing to the deprotonation of citric acid layers, the citric acid-coated magnetic $\mathrm{Fe}_{3} \mathrm{O}_{4}$ nanoparticles exhibited a negative zeta potential of $-22.7 \mathrm{mV}$ at $\mathrm{pH} 7$ (Fig. 3c). While the zeta potential of the original HKUST-1 crystals was $-12.7 \mathrm{mV}$, it increased to a negative value of $-17.5 \mathrm{mV}$ after the formation of HKUST-1@ $\mathrm{Fe}_{3} \mathrm{O}_{4}$ nanocomposite.
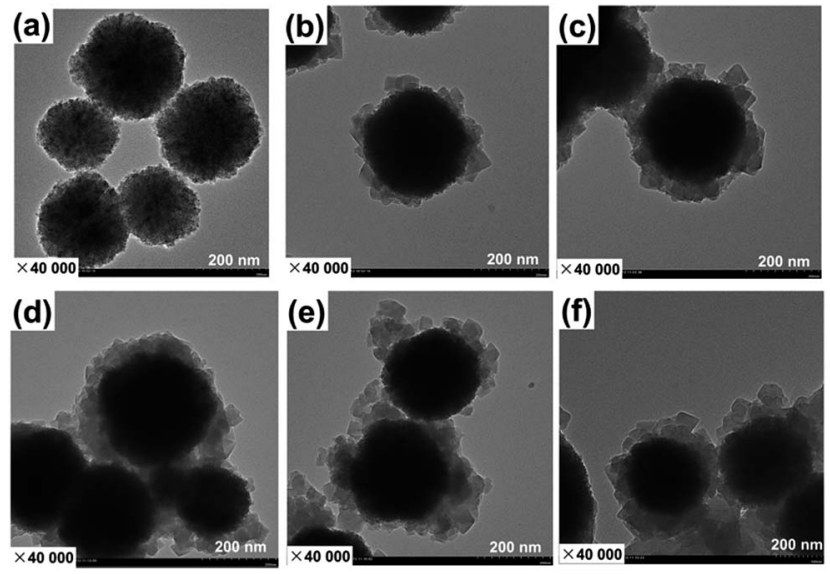

Fig. 1 TEM images of citric acid-coated $\mathrm{Fe}_{3} \mathrm{O}_{4}$ magnetic nanoparticles (a), HKUST-1@ $\mathrm{aFe}_{3} \mathrm{O}_{4}$ (single layer of HKUST-1) (b), HKUST-1@ $\mathrm{aFe}_{3} \mathrm{O}_{4}$ (two layers of HKUST-1) (c), GOx@HRP@HKUST-1@ $\mathrm{aFe}_{3} \mathrm{O}_{4}$ (d), GOxHRP@HKUST-1@ $\mathrm{Fe}_{3} \mathrm{O}_{4}$ (e), and HRP@GOx@HKUST-1@ $\mathrm{Fe}_{3} \mathrm{O}_{4}$ (f).

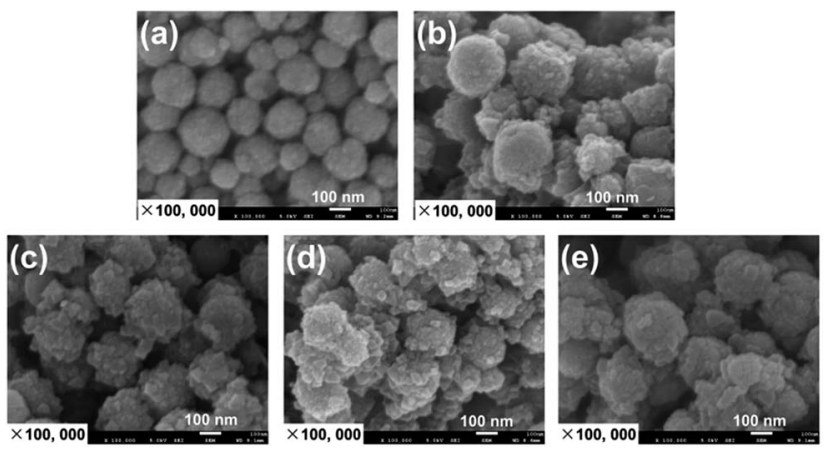

Fig. 2 SEM images of citric acid-coated $\mathrm{Fe}_{3} \mathrm{O}_{4}$ magnetic nanoparticles (a), HKUST-1 $\mathrm{aFe}_{3} \mathrm{O}_{4}$ (two layers of HKUST-1) (b), GOxaHRPaHKUST-1 $\mathrm{aFe}_{3} \mathrm{O}_{4}$ (c), GOx-HRP@HKUST-1@ $\mathrm{Fe}_{3} \mathrm{O}_{4}$ (d), and HRP@GOx@HKUST-1 $\mathrm{aFe}_{3} \mathrm{O}_{4}$ (e).

The TGA plots presented in Fig. 3d indicate that the magnetic $\mathrm{Fe}_{3} \mathrm{O}_{4}$ nanoparticles lost $16.5 \%$ of their weight at $800{ }^{\circ} \mathrm{C}$, which corresponds to the removal of water and citric acid functionalities. TGA of HKUST-1@Fe $\mathrm{F}_{3}$ demonstrates multistage decompositions. The first stage characterized by a weight loss of $5.5 \%$ at $152{ }^{\circ} \mathrm{C}$ is due to the removal of residual coordinated solvent or adsorbed molecules within the HKUST-1 framework. The second weight loss amounting $29.6 \%$ observed between 152 and $500{ }^{\circ} \mathrm{C}$ occurs due to the decomposition of HKUST-1. The third stage observed between 500 and $800{ }^{\circ} \mathrm{C}$ includes the removal of carbon and represents a weight loss of $13 \%$. The residual $48.9 \%$ of weight is copper and iron. Energydispersive X-ray spectroscopy data shown in Table 1 revealed the presence of 23.55 at\% C, 50.63 at\% O, and 25.82 at\% Fe in citric acid-coated $\mathrm{Fe}_{3} \mathrm{O}_{4}$ nanoparticles. The incorporation of HKUST-1 layers changed the elemental compositions to 48.35 at\% C, 40.63 at\% O, 10.16 at\% Fe, and 0.86 at\% Cu. Additionally, due to the porous structures of MOF, the HKUST-1@ $\mathrm{Fe}_{3} \mathrm{O}_{4}$
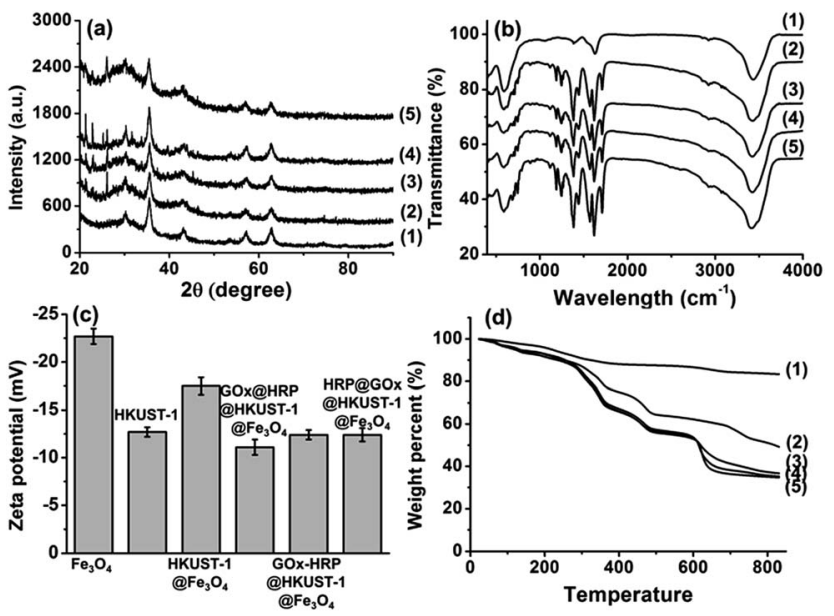

Fig. 3 X-ray diffraction patterns (a), FTIR spectra (b), zeta potentials (c), and thermal gravimetric analysis (d) of citric acid-coated $\mathrm{Fe}_{3} \mathrm{O}_{4}$ magnetic nanoparticles (1), HKUST-1@ $\mathrm{Fe}_{3} \mathrm{O}_{4}$ (two layers of HKUST-1) (2), GOx@HRPaHKUST-1@ $\mathrm{Fe}_{3} \mathrm{O}_{4}$ (3), GOx-HRPaHKUST-1@ $\mathrm{Fe}_{3} \mathrm{O}_{4}$ (4), and HRPaGOx(aHKUST-1 $\mathrm{aFe}_{3} \mathrm{O}_{4}$ (5). 
Table 1 Elemental compositions of citric acid coated $\mathrm{Fe}_{3} \mathrm{O}_{4}$ nanoparticle, and its HKUST-1@Fe $\mathrm{O}_{4}, \mathrm{GOx} @ \mathrm{HRP} @ \mathrm{HKUST}-1 \mathrm{aFe}_{3} \mathrm{O}_{4}$, GOxHRP@HKUST-1 $\mathrm{aFe}_{3} \mathrm{O}_{4}$, and HRP@GOx@HKUST-1@ $\mathrm{Fe}_{3} \mathrm{O}_{4}$ counterparts calculated from energy-dispersive X-ray spectra

\begin{tabular}{|c|c|c|c|c|c|c|}
\hline Nanoparticles & $\mathrm{C}(\mathrm{at} \%)$ & $\mathrm{O}(\mathrm{at} \%)$ & $\mathrm{N}(\mathrm{at} \%)$ & Fe (at\%) & $\mathrm{Cu}(\mathrm{at} \%)$ & $\mathrm{S}(\mathrm{at} \%)$ \\
\hline $\mathrm{Fe}_{3} \mathrm{O}_{4}$ & 23.55 & 50.63 & - & 25.82 & - & - \\
\hline HKUST-1@ $\mathrm{Fe}_{3} \mathrm{O}_{4}$ & 48.35 & 40.63 & - & 10.16 & 0.86 & - \\
\hline GOx-HRP@HKUST-1@Fe $\mathrm{O}_{4}$ & 46.55 & 38.33 & 6.73 & 7.56 & 0.54 & 0.29 \\
\hline HRP@GOx@HKUST-1@Fe $\mathrm{O}_{4}$ & 47.46 & 37.22 & 6.36 & 7.93 & 0.69 & 0.34 \\
\hline
\end{tabular}

nanocomposites exhibited a surface area of $327.6 \mathrm{~m}^{2} \mathrm{~g}^{-1}$, an average pore size of $0.67 \mathrm{~nm}$, and a pore volume of $0.24 \mathrm{~cm}^{3} \mathrm{~g}^{-1}$, all calculated using BET equation.

These results confirmed the successful formation of HKUST1 (a) $\mathrm{Fe}_{3} \mathrm{O}_{4}$ core-shell structures.

\section{Spatial co-localization and positional assembly of GOx/HRP bienzymes using magnetic HKUST-1}

The bienzyme systems were designed to include glucose oxidase and horseradish peroxidase as model enzymes thanks to their robustness and capability to maintain their activity during the immobilization process. ${ }^{3}$ As we demonstrated earlier, the use of multienzyme conjugates for multistage biotransformations is favorable and accelerates the reaction kinetics since a reaction intermediate produced from one enzyme can be directly utilized by the second enzyme without any long distance diffusion or penetration. ${ }^{50}$ However, the cascade reaction kinetics and catalytic efficiency rely on the design of the spatially co-localized multienzyme systems. In this respect, we prepared three different enzymatic nanosystems using spatially co-localization of HRP and GOx at different sites of HKUST-1 via a layer-by-layer self-assembly approach. The synthetic routes are illustrated in Scheme 1 . The three bienzyme nanosystems GOx@HRP@HKUST-1@ $\mathrm{Fe}_{3} \mathrm{O}_{4}$, HRP@GOx@HKUST-1@Fe $\mathrm{O}_{4}$, and GOx-HRP@HKUST-1@ $\mathrm{Fe}_{3} \mathrm{O}_{4}$ vary through GOx and HRP location. The enzymes were either encapsulated in the HKUST-1 inner layer, or immobilized at the HKUST-1 outer shell, or randomly distributed within the two MOF layers. The TEM and SEM images of the three bienzyme conjugates containing GOx and HRP at different locations shown in Fig. 1d-f and $2 \mathrm{c}-\mathrm{e}$ confirm that there is no difference in morphologies. MOF shells with an average thickness of $46 \mathrm{~nm}$ were formed via the aggregation of HKUST-1 nanocrystals with encapsulated enzymes. Fig. 3a shows that the crystal structure and crystallinity did not exhibit any remarkable differences that could be observed between immobilized enzyme nanosystems and generic $\mathrm{Fe}_{3} \mathrm{O}_{4}$ nanoparticles. The FTIR spectra of three bienzyme nanosystems also correspond well with the HKUST-1@ $\mathrm{Fe}_{3} \mathrm{O}_{4}$ nanocomposites (Fig. 3b). The successful immobilization of enzymes was further confirmed by changes in zeta potential. Although GOx $(\mathrm{pI} \sim 4.2)$ is negatively charged and HRP $(\mathrm{pI} \sim 9.0)$ bears a net positive charge at $\mathrm{pH} 7.0,^{16,51}$ the three bienzyme nanosystems revealed similar zeta potentials of $-11.1,-12.4$, and $-12.4 \mathrm{mV}$, respectively (Fig. 3c). The thermal gravimetric analysis plots shown in Fig. 3d are also similar for all three bienzyme nanosystems. The enzyme decomposition occurred between 152 and $500{ }^{\circ} \mathrm{C}$ in which weight losses of $35.8 \%, 37.6 \%$, and $38.5 \%$ were observed for

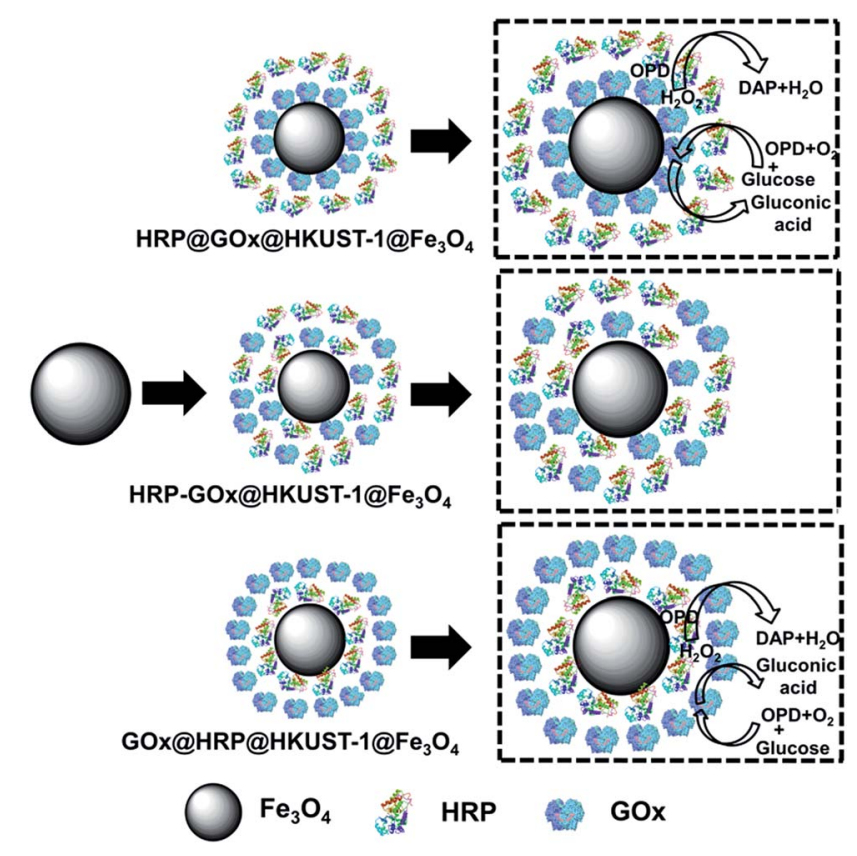

Scheme 1 Schematic illustrations of the three different strategies for the positional assembly and spatial co-localization of GOx and HRP, and their cascade biocatalysis reaction.

GOx@HRP@HKUST-1@Fe $\mathrm{O}_{3}, \mathrm{GOx}-\mathrm{HRP} @ H K U S T-1 @ \mathrm{Fe}_{3} \mathrm{O}_{4}$, and HRP@GOx@HKUST-1@ $\mathrm{Fe}_{3} \mathrm{O}_{4}$, respectively. Furthermore, EDS measurements shown in Table 1 revealed the appearance of sulfur after encapsulation of enzymes in MOF layers.

Enzyme loading and specific activities are summarized in Table 2. For each HKUST-1 layer, the enzyme loading was at the same order of magnitude ranging from 50.9 to $58.9 \mathrm{mg}$ enzyme per gram $\mathrm{Fe}_{3} \mathrm{O}_{4}$ nanoparticles, which was consistent with the TGA results. This is equal to $85 \%$ to $98 \%$ enzyme that were immobilized to the bioconjugates taking into consideration that $3 \mathrm{mg}$ of each free enzyme were added to the system. However, the bienzyme nanosystems with diverse locations of enzymes exhibited significant differences in activity. The GOx@HRP@HKUST-1@Fe $\mathrm{O}_{3}$ nanosystem featured the highest activity, which was $79 \mathrm{U} \mathrm{mg}^{-1}$ for GOx. For each multi-enzyme assembly system, the yield is higher than $89 \%$.

\section{Cascade enzymatic catalysis}

The cascade reaction catalyzed by GOx and HRP includes two steps: first, GOx catalyzes the oxidation of glucose to gluconic 
Table 2 Enzyme loading capacities and specific activities of GOx and HRP which were positionally assembled in magnetic HKUST-1 nanoparticles via three different strategies

\begin{tabular}{|c|c|c|c|}
\hline $\begin{array}{l}\text { Positionally } \\
\text { assembled strategies }\end{array}$ & Enzyme & $\begin{array}{l}\text { Enzyme } \\
\text { loading capacity } \\
\left(\mathrm{mg} \text { per } \mathrm{g} \mathrm{Fe}_{3} \mathrm{O}_{4}\right)\end{array}$ & $\begin{array}{l}\text { Specific } \\
\text { activity } \\
\left(\mathrm{U} \mathrm{mg}^{-1}\right)\end{array}$ \\
\hline GOx@HRP@HKUST- & GOx & 58.2 & 79 \\
\hline $1 @ \mathrm{Fe}_{3} \mathrm{O}_{4}$ & HRP & 58.9 & \\
\hline GOx-HRP@HKUST- & GOx & 56.2 & 61 \\
\hline $1 @ \mathrm{Fe}_{3} \mathrm{O}_{4}$ & HRP & 57.4 & \\
\hline HRP@GOx@HKUST- & HRP & 55.2 & 69 \\
\hline $1 @ \mathrm{Fe}_{3} \mathrm{O}_{4}$ & GOx & 50.9 & \\
\hline
\end{tabular}

acid and hydrogen peroxide by using molecular oxygen as an electron acceptor. Then, HRP converts $\mathrm{H}_{2} \mathrm{O}_{2}$ intermediate to water and oxygen. The continuous decomposition of hydrogen peroxide is favorable since it protects GOx from deactivation and also accelerates the oxidation reaction.

We first tested the cascade biocatalysis performances with GOx-HRP@HKUST-1@Fe $\mathrm{O}_{3}$ bienzyme nanosystem by comparing the glucose conversion at different $\mathrm{pH}(4-7)$ and temperature $\left(15-50{ }^{\circ} \mathrm{C}\right)$ ranges. As illustrated in Fig. $4 \mathrm{a}$ and b, the highest consumption of glucose was observed at pH 6 and the optimum temperature was found to be $20{ }^{\circ} \mathrm{C}$. This result is consistent with previous reports..$^{52-54}$

Another factor affecting the cascade reaction is the reaction time. The three bienzyme nanosystems were used to catalyze reaction of $2 \mathrm{~mL}$ glucose solution with a concentration of $5.55 \mathrm{mmol} \mathrm{L}^{-1}$. Fig. 4c shows that the GOx@HRP@HKUST1 (a) $\mathrm{Fe}_{3} \mathrm{O}_{4}$ nanosystem enabled an almost $100 \%$ conversion of glucose after $15 \mathrm{~h}$. In contrast, 36 and $48 \mathrm{~h}$ were needed to achieve the complete conversion of glucose to gluconic acid reaction conditions of $\mathrm{pH} 6$ and a temperature of $20^{\circ} \mathrm{C}$. The reaction rate was assayed by calculating the consumption of

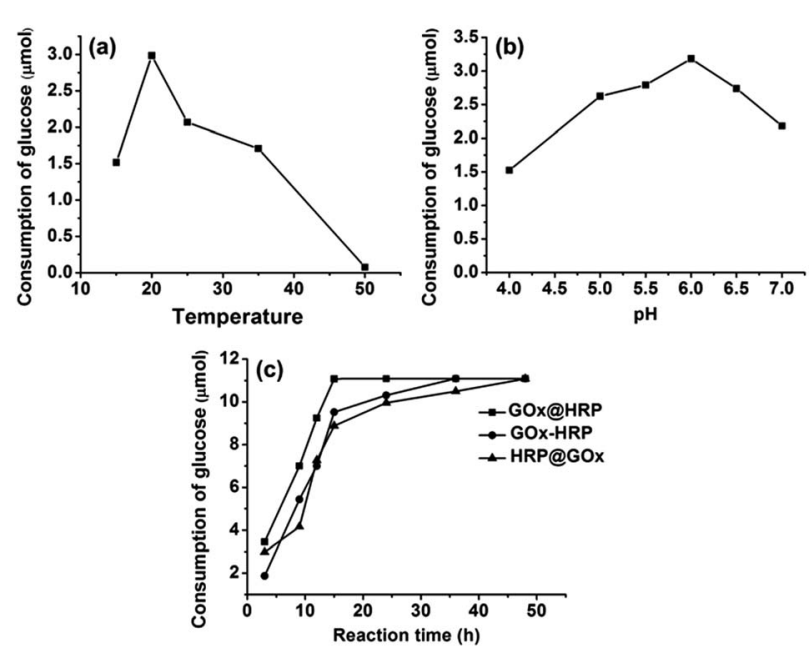

Fig. 4 Effects of different reaction conditions including temperature (a), $\mathrm{pH}$ (b), and reaction time (c) on the consumption of glucose substrate. The reaction was carried out at $\mathrm{pH} 7$ for $3 \mathrm{~h}$ in (a), at a temperature of $20^{\circ} \mathrm{C}$ for $3 \mathrm{~h}$ in (b), and at $\mathrm{pH} 6$ and a temperature of $20{ }^{\circ} \mathrm{C}$ for (c). Glucose concentration $1 \mathrm{mg} \mathrm{mL}^{-1}$. using the GOx-HRP@HKUST-1@Fe $\mathrm{O}_{3}$ and HRP@GOx@HKUST-1@ $\mathrm{Fe}_{3} \mathrm{O}_{4}$ nanosystems, respectively. We assume that this remarkable difference in reaction rate can be attributed to the difference in spatial co-localization of enzymes.

We also studied the effects of GOx/HRP ratio on enzymatic activity. As expected, the bienzyme nanosystem with a GOx/HRP ratio of $1: 4$ produced the highest activity $102 \mathrm{U} \mathrm{mg}^{-1}$ (Table 3).

\section{Kinetics study}

To further elucidate the effect of spatial co-localization of both enzymes on the biocatalysis kinetics, the enzymatic reactions were carried out under the optimized glucose substrate within a concentration range of $0.56-111.1 \mathrm{mmol} \mathrm{L}^{-1}$ at the initial stage of reaction up to consumption of $5 \%$ of glucose substrate. The kinetics curves were drawn by plotting enzymatic reaction rate versus substrate concentration. The Michaelis constant $K_{\mathrm{m}}$ and maximum reaction rate $V_{\max }$ were calculated using glucose and OPD as substrates. Fig. 5 shows that the reaction rate increased with the increase in glucose concentration. At a certain glucose concentration, the bienzyme system became saturated with glucose and reached the maximum reaction rate $V_{\max }$. The Michaelis constant $K_{\mathrm{m}}$ is defined as the substrate concentration at which the enzyme reaction rate is half $V_{\max }$. A lower $K_{\mathrm{m}}$ value corresponds to a higher affinity between the substrate and enzyme, while a higher $V_{\max }$ value reflects a faster reaction rate, and vice versa. As shown in Table 4 , the $K_{\mathrm{m}}$ for all three bienzyme nanosystems was similar with a value of $0.8,0.9$, and $0.7 \mathrm{mmol} \mathrm{L}^{-1}$, respectively. However, the HRP@GOx@HKUST-1@Fe $\mathrm{O}_{4}$ nanosystem with GOx inside and HRP outside exhibited the lowest $V_{\max }$ value of $10.2 \mu \mathrm{mol} \mathrm{L}^{-1} \mathrm{~min}^{-1}$, whereas the GOx@HRP@HKUST-1@ $\mathrm{Fe}_{3} \mathrm{O}_{4}$ nanosystem with HRP inside and GOx outside featured the highest $V_{\max }$ value of 11.3 $\mu \mathrm{mol} \mathrm{L} \mathrm{L}^{-1} \min ^{-1}$. This result was consistent with the data obtained from optimization of reaction time in which the GOx@HRP@HKUST-1@ $\mathrm{Fe}_{3} \mathrm{O}_{4}$ nanosystem required the shortest time of $15 \mathrm{~h}$ to achieve the complete conversion of glucose to gluconic acid, complete conversion of glucose to gluconic acid. In contrast, the HRP@GOx@HKUST-1@ $\mathrm{Fe}_{3} \mathrm{O}_{4}$ nanosystem needed $48 \mathrm{~h}$ to reach the same conversion.

The kinetic parameters listed in Table 4 clearly demonstrate that the reaction rates of the bienzyme nanosystems were closely related to the location of the two enzymes. Scheme 1 illustrates the mechanism of the cascade reaction catalyzed by the three bienzyme nanosystems studied. With regard to the GOx@HRP@HKUST-1@ $\mathrm{Fe}_{3} \mathrm{O}_{4}$ complex in which GOx is

Table 3 Activities of GOx@HRP@HKUST-1@ $\mathrm{aFe}_{3} \mathrm{O}_{4}$ bienzyme nanosystems obtained at different GOx/HRP ratios

\begin{tabular}{lr}
$\begin{array}{l}\text { Bienzyme } \\
\text { nanosystems }\end{array}$ & $\begin{array}{r}\text { Activity } \\
(\mathrm{U} \text { m }\end{array}$ \\
\hline GOx/HRP $(1: 1)$ & 77 \\
GOx/HRP $(1: 2)$ & 87 \\
GOx/HRP $(1: 3)$ & 87 \\
GOx/HRP $(1: 4)$ & 102 \\
GOx/HRP $(1: 5)$ & 86
\end{tabular}



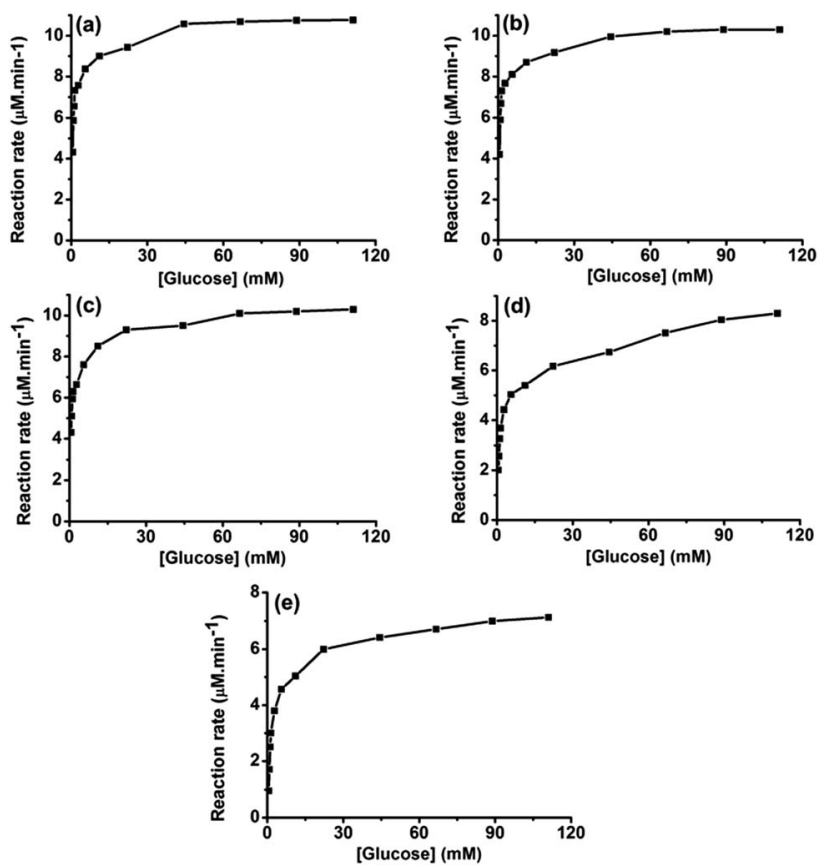

Fig. 5 Kinetic plots depicting the oxidation of glucose catalyzed using our bienzyme nanosystems GOxaHRP@HKUST-1 $\mathrm{aFe}_{3} \mathrm{O}_{4}$ (a), GOxHRPaHKUST-1(aFe $\mathrm{O}_{4}$ (b), HRP@GOxaHKUST-1(a $\mathrm{Fe}_{3} \mathrm{O}_{4}$ (c), individually immobilized enzymes (d), and free enzymes (e). Conditions: $\mathrm{pH} 6$, reaction temperature $20^{\circ} \mathrm{C}$.

localized at the outer shell and HRP in the inner layer of the complex, glucose and oxygen in the solution first access GOx, and are converted to gluconic acid and $\mathrm{H}_{2} \mathrm{O}_{2}$. The $\mathrm{H}_{2} \mathrm{O}_{2}$ intermediate then migrates directly to the HRP enzyme and oxidizes OPD to DAP. This route accelerates the cascade biocatalysis reaction rate.

In contrast, in the case of HRP@GOx@HKUST-1@ $\mathrm{Fe}_{3} \mathrm{O}_{4}$ nanosystem, both glucose and oxygen substrates must first diffuse through the HRP outer layer to approach the GOx inner layer where the first reaction occurs. As a result, the reaction rate is reduced and $V_{\max }$ is much lower. For the GOx-HRP@HKUST-1@ $\mathrm{Fe}_{3} \mathrm{O}_{4}$ nanosystem in which GOx and HRP were randomly distributed in both MOF layers, the reaction rate laid between those observed for each system with separated enzyme layers. It is worth of noting that the

Table 4 Kinetic parameters for the oxidation of glucose to gluconic acid catalyzed by three bienzyme nanosystems and separately immobilized enzymes based on substrate concentrations at a $\mathrm{pH}$ value of 6 and a temperature of $20^{\circ} \mathrm{C}$

\begin{tabular}{|c|c|c|}
\hline & $\begin{array}{l}K_{\mathrm{m}} \\
(\mathrm{mM})\end{array}$ & $\begin{array}{l}V_{\max } \\
\left(\mu \mathrm{M} \min ^{-1}\right)\end{array}$ \\
\hline GOx@HRP@HKUST-1@Fe ${ }_{3} \mathrm{O}_{4}$ & 0.8 & 11.3 \\
\hline GOx-HRP@HKUST-1@Fe ${ }_{3} \mathrm{O}_{4}$ & 0.9 & 10.5 \\
\hline HRP@GOx@HKUST-1@Fe ${ }_{3} \mathrm{O}_{4}$ & 0.7 & 10.2 \\
\hline GOx@HKUST-1@Fe ${ }_{3} \mathrm{O}_{4}+$ & 2.4 & 8.4 \\
\hline HRP@HKUST-1@Fe $\mathrm{O}_{4}$ & & \\
\hline Free enzymes & 2.3 & 7.2 \\
\hline
\end{tabular}

regular pore structures of MOF are favorable to facilitate substrate channeling which enhances cascade biocatalytic performance.

For comparison, we also prepared MOF layers including only a single immobilized enzyme, i.e. GOx@HKUST-1@ $\mathrm{Fe}_{3} \mathrm{O}_{4}$ and HRP@HKUST-1@ $\mathrm{Fe}_{3} \mathrm{O}_{4}$. The cascade reaction was carried out by mixing immobilized GOx with immobilized HRP in glucose solutions at different concentrations. The kinetic curve is presented in Fig. 5d, which as expected reveals a dramatically higher $K_{\mathrm{m}}$ value of $2.4 \mathrm{mmol} \mathrm{L}^{-1}$ and a lower $V_{\max }$ value of 8.4 $\mu \mathrm{mol} \mathrm{L} \mathrm{L}^{-1} \min ^{-1}$ (Table 4). Meanwhile, enzymatic cascade catalysis of glucose and OPD using free GOx and HRP exhibits a much lower $V_{\max }$ value of $7.2 \mu \mathrm{mol} \mathrm{L}{ }^{-1} \mathrm{~min}^{-1}$ as shown in Fig. 5e. This result is consistent with our conclusion that the channeling of the substrate in bienzyme nanosystem enables higher rate of the cascade reaction compared to the situation in which the enzymes are randomly distributed or separately immobilized.

\section{Operational stability and reusability}

The operational stability of the immobilized enzymes is another important parameter that affects the real-life applications. Here, we estimated the operational stability via testing the residual activities of immobilized enzymes in comparison with free enzymes after incubation in phosphate buffer under denaturing conditions including $\mathrm{pH}(2,6$, and 9$)$ and temperature $\left(40,65\right.$, and $\left.95{ }^{\circ} \mathrm{C}\right)$ for $24 \mathrm{~h}$. The initial and residual activities were calculated using glucose as substrate at $20^{\circ} \mathrm{C}$ and pH 6. We discovered that the HKUST-1 immobilized bienzyme system exhibited exceptional stability under harsh conditions, whereas activity of free enzymes rapidly deteriorated. Fig. 6a confirms that free enzymes lost at least $80 \%$ of their initial activities after incubation in phosphate buffer at $\mathrm{pH} 2$ or 9. In contrast, the enzyme-HKUST- 1 conjugates retained more than $70 \%$ of their initial activities after treatment under the same conditions. For example, $93 \%$ and $92 \%$ of residual activity was retained in HRP@GOx@HKUST-1@ $\mathrm{Fe}_{3} \mathrm{O}_{4}$ nanosystem at pH 2 and 9, respectively. At a higher temperature of $65{ }^{\circ} \mathrm{C}$, free enzymes lost $52 \%$ of their initial activities as opposed to only 10\% loss for HRP@GOx@HKUST-1@ $\mathrm{Fe}_{3} \mathrm{O}_{4}$ (Fig. 6b). At a high temperature of $95^{\circ} \mathrm{C}$, free enzymes lost their activity completely while the HRP@GOx@HKUST-1@ $\mathrm{Fe}_{3} \mathrm{O}_{4}$ nanosystem retained $21 \%$ residual activity. The superiority in the high chemical and thermal stability of immobilized enzymes can be ascribed to the protecting effects of HKUST-1. Under harsh conditions that typically result in enzyme denaturation and deactivation, MOFs that act as solid scaffolds for enzyme immobilization are favorable since they help to preserve protein folding thus maintaining the activity. This finding is in agreement with previously reported studies. ${ }^{40,41}$ Comparing the GOx@HRP@HKUST-1@ $\mathrm{Fe}_{3} \mathrm{O}_{4}$ and HRP@GOx@HKUST-1@Fe $\mathrm{O}_{3}$ bioconjugate nanosystems, the latter exhibited better thermal and chemical tolerance. This result can be explained by the fact that the rate controlling reaction is oxidation of glucose catalyzed by GOx and the HKUST-1 outer layer protects better the inner layer containing GOx. 


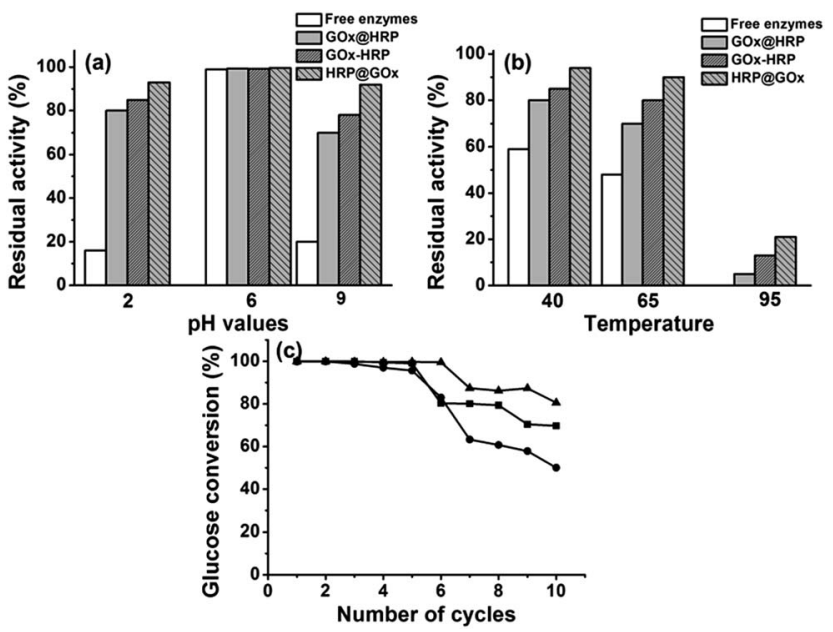

Fig. 6 Operational stabilities of free enzymes in comparison to three bienzyme nanosystems at different $\mathrm{pH}$ values $(2,6$, and 9) (a) and different temperatures $\left(40,65\right.$, and $\left.95^{\circ} \mathrm{C}\right)(\mathrm{b})$, and reusability of three bienzyme nanosystems with respect to the number of cycles the conjugates were used for (c).

The utilization of magnetic $\mathrm{Fe}_{3} \mathrm{O}_{4}$ nanoparticles facilitates the reuse of immobilized enzymes. In this respect, we also determined the reusability of our bienzyme nanosystems by repeatedly catalyzing $2 \mathrm{~mL} 0.5 \mathrm{mg} \mathrm{mL}^{-1}$ glucose substrate solution under the same reaction conditions of $20^{\circ} \mathrm{C}, \mathrm{pH} 6$, and a reaction time of $15 \mathrm{~h}$. As illustrated in Fig. 6c, the HRP@GOx@HKUST-1@ $\mathrm{Fe}_{3} \mathrm{O}_{4}$ nanosystem again had the best operational stability with a glucose conversion of $80.6 \%$ even after repeated use for ten cycles. This result further proves our previous conclusion that the positioning of GOx in the inner HKUST-1 layer is more beneficial to retain its activity. Meanwhile, all three bienzyme nanosystems kept up to $96 \%$ of their initial activities after storing at $4{ }^{\circ} \mathrm{C}$ for more than three weeks.

\section{Conclusions}

We demonstrated the preparation of three recyclable multienzyme nanosystems using magnetic metal-organic framework HKUST-1 as scaffold. These nanosystems contained GOx and HRP with different spatial co-localizations that clearly influenced the cascade reaction kinetics and operational stability of immobilized enzymes. We discovered that the bienzyme nanosystem with GOx on the outer MOF layer and HRP in the inner HKUST-1 layer enabled a faster reaction rate and enhanced the cascade biocatalysis, whereas, the opposite positioning approach is advantageous to improve the thermal and chemical resistance of enzymes. This suggests an interesting strategy that enables precise positioning of multienzymes and possible control of active site orientation. Our results confirm that immobilization of enzymes using MOFs is a promising approach that can lead to design of the artificial biomimetic reactors simulating processes in living cells and to achieve extracellular biosynthesis.

\section{Acknowledgements}

The authors gratefully acknowledge the financial support from National Natural Science Foundation of China (21576017, 21436002, and 21606016), 973 programs (2014CB745100), 863 programs (2015BAD15B07), the Higher Education and HighQuality and World-Class Universities (PY201613), and the Public Hatching Platform for Recruited Talents of Beijing University of Chemical Technology.

\section{Notes and references}

1 G. G. Hammes and C. W. Wu, Science, 1971, 172, 1205.

2 A. S. Shaw and E. L. Filbert, Nat. Rev. Immunol., 2009, 9, 47. 3 J. L. Lin, L. Palomec and I. Wheeldon, ACS Catal., 2014, 4, 505.

4 J. Fu, M. Liu, Y. Liu, N. W. Woodbury and H. Yan, J. Am. Chem. Soc., 2012, 134, 5516.

5 O. I. Wilner, Y. Weizmann, R. Gill, O. Lioubashevski, R. Freeman and I. Willner, Nat. Nanotechnol., 2009, 4, 249.

6 J. E. Dueber, G. C. Wu, G. R. Malmirchegini, T. S. Moon, C. J. Petzold, A. V. Ullal, K. L. J. Prather and J. D. Keasling, Nat. Biotechnol., 2009, 27, 753.

7 C. J. Delebecque, A. B. Lindner, P. A. Silver and F. A. Aldaye, Science, 2011, 333, 470.

8 H. Cheng, L. Zhang, J. He, W. Guo, Z. Zhou, X. Zhang, S. Nie and H. Wei, Anal. Chem., 2016, 88, 5489.

9 O. V. Zore, A. Pattammattel, S. Gnanaguru, C. V. Kumar and R. M. Kasi, ACS Catal., 2015, 5, 4979.

10 R. Qu, L. Shen, A. Qu, R. Wang, Y. An and L. Shi, ACS Appl. Mater. Interfaces, 2015, 7, 16694.

11 V. Linko, M. Eerikainen and M. A. Kostiainen, Chem. Commun., 2015, 51, 5351.

12 L. Lin, J. Yan and J. Li, Anal. Chem., 2014, 86, 10546.

13 X. Ji, Z. Su, P. Wang, G. Ma and S. Zhang, ACS Catal., 2014, 4, 4548.

14 D. Grafe, J. Gaitzsch, D. Appelhans and B. Voit, Nanoscale, 2014, 6, 10752.

15 X. Wang, Z. Li, J. Shi, H. Wu, Z. Jiang, W. Zhang, X. Song and Q. Ai, ACS Catal., 2014, 4, 962.

16 H. Liang, S. Jiang, Q. Yuan, G. Li, F. Wang, Z. Zhang and J. Liu, Nanoscale, 2016, 8, 6071.

17 X. Wu, J. Ge, C. Yang, M. Hou and Z. Liu, Chem. Commun., 2015, 51, 13408.

18 H. Gustafsson, A. Kuchler, K. Holmberg and P. Walde, J. Mater. Chem. B, 2015, 3, 6174.

19 L. Zhou, W. Tang, Y. Jiang, L. Ma, Y. He and J. Gao, RSC Adv., 2016, 6, 90061.

20 G. Begum, W. B. Goodwin, B. M. deGlee, K. H. Sandhage and N. Kroger, J. Mater. Chem. B, 2015, 3, 5232.

21 W. Siti, H.-P. M. de Hoog, O. Fischer, W. Y. Shan, N. Tomczak, M. Nallani and B. Liedberg, J. Mater. Chem. B, 2014, 2, 2733.

22 C. A. Liao, Q. Wu, Q. C. Wei and Q. G. Wang, Chem.-Eur. J., 2015, 21, 12620.

23 M. Onda, Y. Lvov, K. Ariga and T. Kunitake, Biotechnol. Bioeng., 1996, 51, 163. 
24 B. El-Zahab, H. Jia and P. Wang, Biotechnol. Bioeng., 2004, 87, 178.

25 Z. Li, Y. Zhang, Y. Su, P. Ouyang, J. Ge and Z. Liu, Chem. Commun., 2014, 50, 12465.

26 V. Liljeström, J. Mikkilä and M. A. Kostiainen, Nat. Commun., 2014, 5, 4445.

27 J. Rocha-Martin, S. Velasco-Lozano, J. M. Guisan and F. Lopez-Gallego, Green Chem., 2014, 16, 303.

28 E. T. Hwang, B. K. Seo, M. B. Gu and A. P. Zeng, Catal. Sci. Technol., 2016, 6, 7267.

29 J. Fu, M. Liu, Y. Liu and H. Yan, Acc. Chem. Res., 2012, 45, 1215.

30 Y. Hu, F. Wang, C.-H. Lu, J. Girsh, E. Golub and I. Willner, Chem.-Eur. J., 2014, 20, 16203.

31 E. A. Jeffrey, D. Brodin and C. A. Mirkin, Proc. Natl. Acad. Sci. U. S. A., 2015, 112, 4564.

32 D. M. Vriezema, P. M. L. Garcia, N. Sancho Oltra, N. S. Hatzakis, S. M. Kuiper, R. J. M. Nolte, A. E. Rowan and J. C. M. van Hest, Angew. Chem., Int. Ed., 2007, 119, 7522.

33 J. Garcia, Y. Zhang, H. Taylor, O. Cespedes, M. E. Webb and D. Zhou, Nanoscale, 2011, 3, 3721.

34 X. Ji, Z. Su, P. Wang, G. Ma and S. Zhang, ACS Nano, 2015, 9, 4600.

35 A. Alshammari, M. G. Posner, A. Upadhyay, F. Marken, S. Bagby and A. Ilie, ACS Appl. Mater. Interfaces, 2016, 8, 21077. 36 C. Hou, Y. Wang, Q. Ding, L. Jiang, M. Li, W. Zhu, D. Pan, H. Zhu and M. Liu, Nanoscale, 2015, 7, 18770.

37 X. Wu, M. Hou and J. Ge, Catal. Sci. Technol., 2015, 5, 5077. 38 J. R. Long and O. M. Yaghi, Chem. Soc. Rev., 2009, 38, 1213. 39 Y. Chen, S. Han, X. Li, Z. Zhang and S. Ma, Inorg. Chem., 2014, 53, 10006.
40 K. Liang, R. Ricco, C. M. Doherty, M. J. Styles, S. Bell, N. Kirby, S. Mudie, D. Haylock, A. J. Hill, C. J. Doonan and P. Falcaro, Nat. Commun., 2015, 6, 7240.

41 H. Zhang, Y. Lv, T. Tan and D. van der Spoel, J. Phys. Chem. B, 2016, 120, 477.

42 F. Lyu, Y. Zhang, R. N. Zare, J. Ge and Z. Liu, Nano Lett., 2014, 14, 5761.

43 X. Wu, C. Yang, J. Ge and Z. Liu, Nanoscale, 2015, 7, 18883.

44 F. K. Shieh, S. C. Wang, C. I. Yen, C. C. Wu, S. Dutta, L. Y. Chou, J. V. Morabito, P. Hu, M. H. Hsu, K. C. W. Wu and C. K. Tsung, J. Am. Chem. Soc., 2015, 137, 4276.

45 S. Schoffelen and J. C. M. van Hest, Soft Matter, 2012, 8, 1736.

46 J. Liu, Z. Sun, Y. Deng, Y. Zou, C. Li, X. Guo, L. Xiong, Y. Gao, F. Li and D. Zhao, Angew. Chem., Int. Ed., 2009, 121, 5989.

47 Y. Cao, L. Wen, F. Svec, T. Tan and Y. Lv, Chem. Eng. J., 2016, 286, 272.

48 F. N. Azad, M. Ghaedi, K. Dashtian, S. Hajati and V. Pezeshkpour, Ultrason. Sonochem., 2016, 31, 383.

49 S. Mosleh, M. R. Rahimi, M. Ghaedi, K. Dashtian and S. Hajati, RSC Adv., 2016, 6, 17204.

50 C. Garcia-Galan, Á. Berenguer-Murcia, R. FernandezLafuente and R. C. Rodrigues, Adv. Synth. Catal., 2011, 353, 2885.

51 J. H. Pazur and K. Kleppe, Biochemistry, 1964, 3, 578.

52 C. M. Wong, K. H. Wong and X. D. Chen, Appl. Microbiol. Biotechnol., 2008, 78, 927.

53 J. L. Munoz-Munoz, F. Garcia-Molina, R. Varon, J. N. Rodriguez-Lopez, F. Garcia-Canovas and J. Tudela, Biosci., Biotechnol., Biochem., 2007, 71, 390.

54 D. Lan, B. Li and Z. Zhang, Biosens. Bioelectron., 2008, 24, 934. 